1

\title{
Forced response and internal variability of summer climate over
}

\section{western North America}

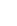

Youichi Kamae ${ }^{1,2^{*}}$, Hideo Shiogama ${ }^{3}$, Yukiko Imada ${ }^{4}$, Masato Mori ${ }^{5}$, Osamu Arakawa ${ }^{1}$, Ryo Mizuta ${ }^{4}$, Kohei Yoshida ${ }^{4}$, Chiharu Takahashi ${ }^{5}$, Miki Arai $^{5}$, Masayoshi Ishii ${ }^{4}$, Masahiro Watanabe ${ }^{5}$ Masahide Kimoto ${ }^{5}$, Shang-Ping $\mathrm{Xie}^{2}$, and Hiroaki Ueda ${ }^{1}$

${ }^{1}$ Faculty of Life and Environmental Sciences, University of Tsukuba, Tsukuba, Ibaraki, Japan

${ }^{2}$ Scripps Institution of Oceanography, University of California San Diego, La Jolla, California, USA

${ }^{3}$ Center for Global Environmental Research, National Institute for Environmental Studies, Tsukuba, Ibaraki, Japan

${ }^{4}$ Meteorological Research Institute, Tsukuba, Ibaraki, Japan

${ }^{5}$ Atmosphere and Ocean Research Institute, University of Tokyo, Kashiwa, Chiba, Japan

Submitted to Climate Dynamics

\footnotetext{
*Corresponding author: Youichi Kamae, Faculty of Life and Environmental Sciences, University of Tsukuba, 1-1-1 Tennoudai, Tsukuba, Ibaraki 305-8506, Japan (kamae.yoichi.fw@u.tsukuba.ac.jp), Tel.: $+81-29-853-4757 \quad$ Fax: $+81-29-853-6709$
} 
Over the past decade, anomalously hot summers and persistent droughts frequented over the western

United States (wUS), the condition similar to the 1950s and 1960s. While atmospheric internal variability is

important for mid-latitude interannual climate variability, it has been suggested that anthropogenic external

forcing and multidecadal modes of variability in sea surface temperature (SST), namely, the Pacific Decadal

Oscillation (PDO) and Atlantic Multidecadal Oscillation (AMO), also affect the occurrence of droughts and hot

summers. In this study, 100-member ensemble simulations for 1951-2010 by an atmospheric general circulation

model (AGCM) were used to explore relative contributions of anthropogenic warming, atmospheric internal

variability, and atmospheric response to PDO and AMO to the decadal anomalies over the wUS. By comparing

historical and sensitivity simulations driven by observed sea surface temperature, sea ice, historical forcing

agents, and non-warming counterfactual climate forcing, we found that large portions of recent increases in mean

temperature and frequency of hot summers $(66 \%$ and $82 \%)$ over the wUS can be attributed to the anthropogenic

global warming. In contrast, multidecadal change in the wUS precipitation is explained by a combination of the

negative PDO and the positive AMO after the 2000s. Diagnostics using a linear baroclinic model indicate that

AMO- and PDO-related diabatic heating anomalies over the tropics contribute to the anomalous atmospheric

circulation associated with the droughts and hot summers over wUS on multidecadal timescale. Those anomalies are not robust during the periods when PDO and AMO are in phase. The prolonged PDO-AMO antiphase period since the late 20th century resulted in the substantial component of multidecadal anomalies in temperature and precipitation over the wUS. 
Keywords: Global warming hiatus, PDO, AMO, hot summers, linear baroclinic model 


\section{Introduction}

Since the late 20th century, mean temperature and frequency of warm extremes have both remarkably increased over land (e.g. Hansen et al. 2012; Perkins et al. 2012). Anthropogenic influences including human-induced greenhouse gases emissions play an essential role in the observed climate change during the recent six decades (e.g. Jones et al. 2013; IPCC 2013). In addition, intrinsic variability in the climate system also influences decadal-to-centennial climate trends particularly during the winter season (Hawkins and Sutton 2009;

Deser et al. 2012). Since the end of the 20th century, substantial decadal-to-multidecadal variations (DMV) in the rate of global-mean temperature increase have been observed. Particularly, temperature and precipitation trends during these decades exhibit substantial regionality associated with anomalous atmospheric circulations, suggesting an important role of natural climate variability (e.g. Horling et al. 2010; Wang et al. 2013; Kamae et al. 2014a, b, 2015; Ueda et al. 2015; Gu et al. 2016; Zhou and Wu 2016). The literature suggested an importance of sea surface temperature (SST) DMV over the Indian (Luo et al. 2012), Atlantic (McGregor et al. 2014; Li et al. 2016), and Pacific (Kosaka and Xie 2013; England et al. 2014; Watanabe et al. 2014) Oceans. Anomalous convective activity over the tropics associated with the SST variations can influence mid-latitude climate variations via changing atmospheric circulations (Trenberth et al. 2014; Ding et al. 2014; Ueda et al. 2015).

Climate extremes including multi-year droughts, pluvials and warm extremes have been a recurrent feature of the western United States (wUS; e.g. Cook et al. 2007). Since around the year 2000, extreme hot summers and persistent droughts were frequently observed over the wUS (e.g. Seager and Hoerling 2014; Shiogama et al. 2014; Delworth et al. 2015) despite a slowdown of global-mean surface warming (e.g. Kosaka 
and Xie 2013; Fyfe et al. 2016; detailed in Sects. 3.1 and 3.2). Droughts and heat waves are coupled via land-atmosphere interaction over semi-arid regions (Mueller and Seneviratne 2012). Less precipitation over the wUS tends to be associated with cool SST over the tropical eastern Pacific (e.g. Ting and Wang 1997; Wang and Schubert 2014). In addition to the El Niño Southern Oscillation (ENSO), Pacific SST DMVs associated with the Interdecadal Pacific Oscillation (IPO) or Pacific Decadal Oscillation (PDO; Mantua et al. 1997; Power et al. 1999; Deser et al. 2004; Newman et al. 2016) also contribute to precipitation variability (Seager et al. 2005; Meehl and Hu 2006; Cook et al. 2011; Dai 2013; Seager and Hoerling 2014; Burgman and Jang 2015; Delworth et al. 2015). Other analytical and numerical studies, on the other hand, suggested the importance of Atlantic SST anomaly on the wUS precipitation variation (Sutton and Hodson 2005, 2007; Kushnir et al. 2010; Cook et al. 2011; Feng et al. 2011). Kushnir et al. (2010) revealed that the atmospheric response to deep-tropospheric diabatic heating associated with the warm Atlantic SST contributes to a reduction of precipitation over central North America via changing atmospheric circulations.

Both the anthropogenic influence and the naturally-generated climate variations affect mean SAT, precipitation and climate extremes over the middle latitudes including the wUS (e.g. Meehl et al. 2007; Jones et al. 2013; Shiogama et al. 2014; Diffenbaugh et al. 2015; Xie et al. 2015). However, the forced component of the climate variations is difficult to detect due to the predominant atmospheric internal variability in the middle latitudes. Kamae et al. (2014a) decomposed historical variations of warm extremes over land into anthropogenic influence and naturally-generated climate variation by using 10-member ensemble atmospheric general circulation model (AGCM) simulations. The relative importance of atmospheric internal variability is 
predominant in the variation of the frequency of hot summers over the middle latitudes (Fig. 2c in Kamae et al. 2014a). By using results of ensemble AGCM simulations prescribed with observed SST, contributions of anthropogenic forcing and naturally-generated climate variability to observed climate anomalies including the warm and dry wUS climate in the 2000s can be examined. In addition, coarser resolution models are not well suited for reproducing regional atmospheric circulation and seasonal precipitation patterns over the wUS because the regional climate system is associated with complex terrain (Langford et al. 2014; Brewer and Mass 2016). In this study, we examine the relative importance of anthropogenic influence, atmospheric internal variability, and atmospheric response to naturally-generated SST variation in the historical variations over land including the wUS on different timescales. For this purpose, we use a high-resolution, 100-member ensemble AGCM simulation for 1951-2010. Using the large ensemble enables to examine relative importance of forced atmospheric variation to SST variability modes compared with internal atmospheric variability. We focus on mean temperature, frequency of hot summers, and precipitation over land during boreal summer. Section 2 describes the data and methods including observations, reanalysis and modeled data analyzed in this study. Section 3 presents the historical climate variations over the Northern Hemisphere land areas and the wUS. We also quantify the anthropogenic influence the wUS climate variation. Section 4 examines roles of DMV in SST over the Pacific and Atlantic in the wUS climate variations. Section 5 evaluates relative contributions of forced atmospheric response and internal variability to the historical climate variation on different timescales. In Sect. 6, we present a summary and discussion. 


\section{Data and methods}

\subsection{Observations and reanalysis}

We used CRU TS v3.23 dataset (Harris et al. 2014) as reference data representing the observed climate state for 1901-2010. We used monthly mean surface air temperature (SAT) data in $0.5^{\circ} \times 0.5^{\circ}$ spatial resolution to examine historical variations of mean temperature and frequency of hot summers over land (Sect. 2.4). We mainly used SAT for 1951-2010 to compare with modeled climate variation (Sect. 2.2). For examining surface and three dimensional atmospheric states for 1958-2010, the Japanese 55-year Reanalysis (JRA-55; Kobayashi et al. 2015) was used. Data in $0.5^{\circ} \times 0.5^{\circ}$ and $1.25^{\circ} \times 1.25^{\circ}$ spatial resolutions were used in the analyses for surface and three dimensional variables, respectively. For global precipitation (including over the ocean), the dataset of the Global Precipitation Climatology Project (GPCP; version 2.2; Alder et al. 2003) was used to examine multidecadal precipitation variability during 1979-2010. Historical variations in SST were examined by using HadISST (Rayner et al. 2003) at $1.0^{\circ} \times 1.0^{\circ}$ spatial resolution.

\subsection{Large ensemble in an AGCM}

In this study, large-ensemble historical simulations with a high-resolution AGCM (Mizuta et al. 2016) were used to examine SST- and emission-forced climate response and atmospheric internal variability for 19512010. The Meteorological Research Institute Atmospheric General Circulation Model (MRI-AGCM) version 3.2 (Mizuta et al. 2012) was used for 100-member ensemble historical simulations. The model was run at a horizontal resolution of TL319 (equivalent to 60-km mesh) with 64 vertical layers (Murakami et al. 2012). For 
the ensemble historical simulations (hereafter ALL run), the AGCM was driven by observation-based SST and sea ice (Hirahara et al. 2014) and historical radiative forcing agents (greenhouse gases, aerosols, and ozone) for 1951-2010. The ozone concentration was based on results of Reference Simulation 2 for the Chemistry Climate Models Validation (Eyring et al. 2005) using the MRI Chemical Transport Model (Shibata et al. 2005). The aerosols were derived from the results of a present-day experiment using a prototype version of MRI Earth System Model version 1 (MRI-ESM1; Yukimoto et al. 2011), in which the historical emission flux and the surface emission inventories were prescribed. 5-year running mean of the ozone and aerosols were incorporated into the AGCM. To develop 100-member ensemble, SST perturbations based on SST analysis error (Hirahara et al. 2014) were added to the observed SST to account for uncertainties. The perturbations consist of Empirical Orthogonal Functions (EOFs) of the interannual variations (IAV) of the SST analysis. The amplitude of the perturbation is set to be $30 \%$ of the standard deviation of the interannual SST variability. Spread in climate response due to the perturbed SST is comparable to that due to initial condition perturbations (Mizuta et al. 2016). Sea ice concentration was derived from a quadratic equation on sea-ice-SST relationship (Hirahara et al. 2014). By using the 100-member ensemble, the ensemble mean and the deviation of each member from the ensemble mean can be regarded as approximations of forced atmospheric response and internal variability, respectively (Sect. 5). Note that the ensemble mean is also affected by internal variability modes in the atmosphere-ocean coupled system (e.g. PDO).

In order to decompose anthropogenic warming and naturally-generated climate variations, 100-member non-warming simulations (hereafter NW run) were conducted. Greenhouse gases were fixed at the level of 1850 
while ozone was fixed at the level of 1960 in MRI-ESM1 simulation. Sulfate, black carbon, and organic carbon were fixed at climatology of the pre-industrial simulation. Other prescribed aerosols including soil and sea salt particles were identical to the ALL run. In the NW run, the EOF1 mode of SST during 1951-2010 (Hirahara et al. 2014), which approximately present the linear trend pattern, was removed from the prescribed SST. Here the anthropogenic influence is assumed to be dominant for the linear trend pattern subtracted from the prescribed SST. Note that effects of low-frequency natural climate fluctuations could be reduced by subtracting the linear trends. However, effects of PDO and AMO are almost not removed because both of the two do not show monotonic trends for this period (see Sect. 3.2). Further discussion on the decomposition method can be found in Christidis and Stott (2014) and Shiogama et al. (2014, 2016). The SST perturbation identical to the ALL run was added to the detrended SST. More details on this dataset called Database for Probabilistic Description of Future Climate Change (d4PDF), including experimental setup of the ALL and NW runs, general representation of climatological spatial patterns and historical variation of the current climate, can be found in Mizuta et al. (2016) and Shiogama et al. (2016).

\subsection{Linear baroclinic model}

To diagnose the atmospheric circulation response to specified convective heating associated with DMV over the tropics, we used a linear baroclinic model (LBM; Watanabe and Kimoto 2000) based on primitive equation linearized around the observed June-July-August (JJA) mean atmospheric state as represented by NCEP/NCAR reanalysis. The model used is a version with T42 resolution in the horizontal and 20 sigma levels 
in the vertical. The model was forced by anomalous diabatic heating in the tropical atmosphere. Experimental setups including imposed diabatic heating are described in Sect. 4.2.

\subsection{Definition of hot summers}

In this study, hot summers were defined by using climatology and two standard deviations of monthly-mean SAT (Hansen et al. 2012, Kamae et al. 2014a). First, long-term variability and linear trend for 1958-2010 were extracted from the SAT in each month and at each grid point. Next, climatology and standard deviations were calculated using the period 1958-2010. We define hot summers as those SAT anomalies exceed two standard deviations. The frequency of hot summers in the Northern Hemisphere land areas was calculated by averaging over the area for each month and then averaged during JJA for each year. Previous studies used a shorter period (1951-1980) for calculating climatology and standard deviations (Hansen et al. 2012; Kamae et al. 2014a), and the frequency of hot summers can be biased outside the reference period (Zhang et al. 2005; Sippel et al. 2015). We tested the sensitivity of results to different reference periods and confirmed that interannual and multidecadal variations in frequency of hot summers were qualitatively consistent. However, the amplitudes of the fluctuations were generally larger when the shorter reference period was used. In this study, we used 19582010 as the reference period to avoid exaggerated estimates of the temperature variations outside the reference period.

\section{Anthropogenic and natural variability effects}




\subsection{Global variations} In this section, we examine the general reproducibility of historical climate variations in the ALL run by comparing with observations over the Northern Hemisphere land areas during JJA. Figure 1 shows historical variations of SAT and frequency of hot summers in CRU TS v3.23 (1901-2010), JRA-55 (1958-2010), ALL and NW runs (1951-2010). In all the time series, remarkable IAV, DMV, and long-term increasing trends in SAT and frequency of hot summers can be found since the late 20th century. DMV in SAT is characterized by cooling in the early 20th century (found in CRU TS v3.23) and in the 1960s to 1970s and warming in the 1930s to 1940 s and substantial warming trend from the 1980s to present, similar to other datasets (Jones et al. 2013; IPCC 2013). The ensemble AGCM simulations since 1951 capture both the IAV and DMV including the recent warming period. The IAV in SAT is similar to the NW run because much of the IAV in the ensemble mean is atmospheric response to the SST variations including ENSO (Kamae et al. 2014a). The recent warming period is largely due to the effect of anthropogenic warming, as indicated by the difference between the ALL and NW runs (Sect. 2.2), with contribution from the naturally-generated DMV (Kamae et al. 2014a; Watanabe et al. 2014). In the 2000s, summertime warm extremes were frequently observed compared with the late 20th century (Fig. 1b; Hansen et al. 2012; Kamae et al. 2014a). The Pacific and Atlantic SST DMV (Zhou and Wu 2016) and direct anthropogenic influences (Kamae et al. 2014a) are important for the decadal-scale increase in frequency of hot summers in the early 21 st century despite the slowdown of the annual-mean global-mean SAT increase (e.g. Kosaka and Xie 2013; Fyfe et al. 2016). 
2010 compared with 1978-1999. The averaging periods correspond to different phases of the PDO and AMO (detailed below). Both JRA-55 and CRU TS v3.23 (not shown) exhibit statistically-significant warming over the broad land areas particularly in the mid-latitude Northern Hemisphere (Fig. 2a; Kamae et al. 2014a, b). Although the ensemble mean of the ALL runs (Fig. 2b) also shows a large warming over the middle latitude, it does not reproduce the substantial spatial asymmetry in observations (e.g. cold anomalies over Central Canada and Central Asia and amplified warming over Central and Eastern Europe and East Asia; Fig. 2a), suggesting the importance of internal atmospheric variability and/or the effect of model biases.

Over the last decade, the substantial increases in SAT and extremely warm events with persistent drought were found over the wUS $\left(150^{\circ} \mathrm{W}-120^{\circ} \mathrm{W} ; 25^{\circ} \mathrm{N}-50^{\circ} \mathrm{N}\right.$; black rectangle in Fig. 2), distinct from the eastern US (Fig. 2a, c; Meehl et al. 2012; Sheffield et al. 2013; Perin et al. 2016). The ensemble mean of the AGCM runs can partly capture the warming and increasing warm extremes over the wUS (Fig. 2b. d), suggesting the importance of forced atmospheric response on the multidecadal timescale. In the next section, we focus on IAV and DMV of the wUS summertime climate.

\subsection{Western US}

Figure 3 shows historical variations of SAT, frequency of hot summers and precipitation over the wUS.

Large variations can be found on interannual and multidecadal timescales: warm and dry periods in the 1950s, 1960s and 2000s and cool and humid periods in the 1980s to 1990s, consistent with previous reports (e.g. Seager 

2006; Fig. 3a-c), suggesting the importance of mid-latitude stochastic internal variability in the atmospheric 1990s and the dry 1950s and 2000s) is found in the ALL run (Fig. 3d-f). Note that the ensemble mean of the

217 AGCM simulations does not reproduce the reduced precipitation in the 1970s relative to the 1960s (Fig. 3f). The DMV which are simulated in the ALL run are also found in the NW run (except the long-term warming trend), suggesting the important contributions from the naturally-generated SST variations. Here differences in decadal time series between ALL and NW runs are found in SAT and frequency of hot summers (ALL run shows lower and higher values than NW run before and after the 1970s, respectively) but are not apparent for precipitation (Fig. 3d-f), suggesting different contributions of naturally-generated DMV to temperature and precipitation. The anomalies averaged for 2000-2010 compared with 1978-1999 are summarized in Table 1. The observed high

SAT, frequent hot summers, and reduced precipitation are qualitatively reproduced in the ensemble mean of ALL run and these anomalies are statistically significant. The majority of the warming and increasing frequency of hot

result from the NW simulation. As for precipitation, naturally-generated variations contribute to $44 \%$ of the regional DMV (Wallace et al. 2015; see Sect. 4) are important for both precipitation and temperature in the wUS, 
AMO. Figure $3 \mathrm{~g}$ shows 11-yr running means of PDO index (http://research.jisao.washington.edu/pdo/) and

AMO index from Trenberth and Shea (2006; http://www.cgd.ucar.edu/cas/catalog/climind/AMO.html) based on

HadISST (Rayner et al. 2003) for 1901-2010. Since the late 20th century, PDO and AMO tend to have opposite

signs. During the period with negative PDO and positive AMO (1951-1965 and 2003-2010), the wUS tends to

be warmer and dryer (Fig. 3d-f) compared with the period with positive PDO and negative AMO (1978-1999;

Fig. 3d-f). The recent global-warming hiatus (e.g. Delworth et al. 2015) is concurrent with a negative PDO and positive AMO.

The Pacific and Atlantic SST variations influence the wUS climate on interannual-to-multidecadal

timescales (e.g. Seager et al. 2005; Meehl and Hu 2006; Cook et al. 2011; Dai 2013). Despite the dominant role

of ENSO in IAV in wintertime precipitation, the Atlantic Ocean contributes substantially to the summertime 


\section{Global variability associated with the western-US climate on decadal-to-multidecadal timescale}

\subsection{SST, atmospheric circulation and precipitation} positive AMO" periods (1951-1968 and 2003-2010) minus “positive PDO and negative AMO” period (19781999). Substantial regionality in the precipitation anomaly including reduced precipitation over the mid-latitude wUS (Figs. 3c, f, 4a) and East Asia (Ueda et al. 2015) is accompanied with negative tropical eastern Pacific and positive North Atlantic SST anomalies (Fig. 4c). Meanwhile, increased precipitation is found over tropical Central and South America (Fig. 4a). These precipitation anomalies can be found in the AGCM simulations with statistical significance (Fig. 4b). The NW run also exhibits a similar precipitation pattern (Fig. S1 in the online supplement). The interhemispheric SST gradient between the Northern (warm) and Southern (cool) Atlantic associated with the AMO (Fig. 4c) intensifies summertime rainfall in the intertropical convergence zone (ITCZ) 
Figs. 4b and 5b, respectively), except the high SST anomaly over the mid-latitude eastern North Pacific (140 ${ }^{\circ} \mathrm{W}$;

SST is also important for the DMV in wUS precipitation in addition to the eastern Pacific SST. minus 1979-1999). Note that the comparing period is slightly different from Fig. 4 because of limited data 
with an intensified North Pacific anticyclone (positive geopotential height over the North Pacific; Fig. 7a) results in a reduction of summertime precipitation over the wUS (Figs. 4a, 6; e.g. Dai 2013). In addition, the warm tropical Atlantic (Fig. 4c) induces Gill-type atmospheric response (i.e. anomalous upper-level subtropical anticyclones over Africa, Atlantic Ocean and America; Kamae et al. 2014a, and low-level cyclonic circulation including easterly over Florida and westerly over south of Gulf of Mexico) and resultant reduction of moisture advection from the Gulf of Mexico to Central North America (Fig. 7a; Kushnir et al. 2010; Feng et al. 2011; Hu and Feng 2012). The observed anomalies above are consistent with those in the ensemble mean of the ALL run (Fig. 7b) and the NW run (Fig. S2 in the online supplement), indicating a contribution of forced atmospheric response to the natural DMV in SST (Fig. 4c). In addition, a mid-latitude wave-like pattern from the Pacific to Atlantic (positive upper-level geopotential height anomaly over the North Pacific, south of Greenland, the Canary Islands and negative anomaly over Canada and North Atlantic) can be found both in observations and the forced atmospheric response in the AGCM run (Fig. 7a, b). Note that the forced atmospheric response to the SST DMV obtained from the ensemble mean is generally smaller than that in the reanalysis, suggesting an important role of atmospheric internal variability.

\subsection{Atmospheric response to tropical forcing}

During the period from the end of the 20th century to the early 21 st century, the large DMV in the tropical

SST affects the mid-latitude climate by changing tropical convection and atmospheric circulations (Trenberth et al. 2014; Ding et al. 2014; Ueda et al. 2015). To understand physical relationship between the DMV in tropical 
precipitation (Figs. 4, 6) and the middle latitude atmospheric circulation (Fig. 7), idealized simulations were

performed by using LBM (Sect. 2.3). In Fig. 6, statistically-significant precipitation anomalies on multidecadal timescale are found on the edge of ITCZ in the tropical eastern Pacific (ePac; centered at $\left.140^{\circ} \mathrm{W}, 20^{\circ} \mathrm{N}\right)$ and over the tropical Atlantic-to-African ITCZ (tAtl; centered at $5^{\circ} \mathrm{W}, 12^{\circ} \mathrm{N}$; rectangles in Fig 6). It is worthwhile to note that these precipitation anomalies cannot be found during the in-phase period of the PDO and AMO (Fig. 5).

Figure 8 shows profiles of climatological condensational heating over ePac and tAtl. Near-surface cooling associated with the evaporation of cloud water is common to both regions while substantial heating is found in the lower troposphere over ePac and in the middle troposphere over tAtl (e.g. Yanai and Tomita 1998; Shige et al. 2008; Hagos et al. 2010). Peak levels of anomalies associated with the DMV are similar to the climatologies over ePac (not shown) and tAtl (Fig. 5b in Kushnir et al. 2010). To conduct LBM simulations, tropospheric cooling and heating were made based on area-averaged precipitation anomalies in Fig. 6. The imposed heating exhibits an oval shape with a spread of $40^{\circ}\left(50^{\circ}\right)$ longitude and $12^{\circ}$ latitude over ePac (tAtl) with a heating maximum at the center. Over ePac (tAtl), the cooling (heating) has a shallow (deep) vertical structure that peaks at $\sim 900$ (450) $\mathrm{hPa}$, where the maximum cooling (heating) rate is $-0.43(0.19) \mathrm{K} \mathrm{day}^{-1}$. The response at day 20 is analyzed when the model reaches a quasi-steady state.

Figure 9 shows quasi-steady atmospheric responses to the tropical heating/cooling. The diabatic cooling due to the reduced condensation heat release over ePac (blue circle in Fig. 9a) induces a local low-level cyclonic anomaly over the tropical Pacific and upper-level anticyclonic anomaly over the North Pacific. In the lower troposphere, an anticyclonic circulation anomaly and northerly anomaly can be found over the North Pacific and 
the wUS (Fig. 9a). The upper-level wave-like pattern from the mid-latitude Pacific to Atlantic (Fig. 9a) is similar to observations and the ALL run (Fig. 7). The heating anomaly over tAtl results in upper-level subtropical anticyclones and low-level cyclonic circulation over the Gulf of Mexico (easterly over Florida and westerly over south of Gulf of Mexico; Fig. 9b; Kushnir et al. 2010; Feng et al. 2011), consistent with observations (Fig. 7).

These results indicate that the atmospheric responses to the two condensational heating can largely explain the observed anomalies in the atmospheric circulation over the Pacific to Atlantic Oceans and associated wUS precipitation (Figs. 4, 6, 7). Note that the simulated steady responses in the geopotential height and atmospheric circulation are relatively weaker than observations and the ALL run. Contributions from other factors including middle latitude SST anomalies may also be important for the DMV in atmospheric circulation and precipitation (Ting and Wang 1997; Burgman and Jang 2015).

\section{Internal variability and forced atmospheric response}

As shown in the previous sections, the forced atmospheric responses to the SST DMV associated with PDO and AMO over the wUS (Figs. 4b, 7b) are consistent with observations since the late 20th century (Figs. 4a, 6, 7a) when the PDO and AMO tend to be opposite in phase (Figs. 3-5). The idealized model simulation also supports the tropical influence on the DMV in the mid-latitude atmospheric circulation (Fig. 9). These results suggest that the forced atmospheric response to the SST DMV is important for the DMV in mid-latitude climate despite internal atmospheric variability (e.g. Deser et al. 2012). In this section, we compared forced signal and 
internal atmospheric variability using the ensemble simulations. Here a ratio $R$ of forced response to internal variability (signal-to-noise ratio; Mei et al. 2014, 2015) can be determined as:

$$
R=\frac{\sigma_{F}}{\sigma_{I}}
$$

where $\sigma_{F}$ (forced response) is the standard deviation of the ensemble mean and $\sigma_{I}$ (internal variability) is the standard deviation of the departures from the ensemble mean in the 100 members. Before the calculation, long-term trends (for 1951-2010) were removed from variables. A large $R$ indicates a relatively important role of forced response compared with internal variability and thus a high potential predictability. We examine $R$ on two different timescales: interannual (shorter than 15 years) and multidecadal (longer than or equal to 15 years). To examine $R$ on multidecadal timescales, 15-yr running mean of given variables were used for calculating $\sigma_{F}$ and $\sigma_{I}$. Residuals obtained by removing the running mean were used for calculation $R$ on interannual timescale. We also tested results by using other criteria (e.g. 11 years) and confirmed that spatial patterns and relative importance (detailed below) were not sensitive to selection of criteria.

Figure 10 compares $R$ during JJA for 1951-2010 on the two timescales. In general, contribution of atmospheric internal variability to the mid-latitude high-frequency (shorter than 15 years) variability is dominant (Fig. 10a, c; e.g. Madden 1976). In the middle latitudes, $R$ is larger (i.e. the relative contribution of SST-forced response becomes more dominant) for low-frequency (longer than or equal to 15 years) variability (Fig. 10b, d) than for the high-frequency variability (Fig. 10a, c). $R$ is also larger over the tropics and Greenland on the longer timescale. Although large $R$ values in precipitation on both timescales are generally confined to the tropics (Fig. 10c, d), they can also be found over the mid-latitude wUS, North Africa, northern India and southeastern China. 
362

363

364

These results suggest a potential higher predictability of the SAT and precipitation on multidecadal than interannual timescale. Figure 11 shows $R$ during December, January and February. The dominant role of middle-latitude atmospheric internal variability during boreal winter (e.g. Deser et al. 2012) results in a smaller $R$ than JJA. For mid-latitude SAT, $R$ is also larger on multidecadal than interannual timescale (Fig. 11a, b), although $R$ for wintertime precipitation is not substantially different between the two timescales (Fig. 11c, d). We also confirmed that results of the NW run (Figs. S3 and S4 in the online supplement) are generally similar to Figs. 10 and 11 because long-term trend were removed before calculating $R$ and IAV and DMV are similar between the two runs.

The prolonged periods with oppositely phased PDO and AMO since the late 20th century result in the substantial forced atmospheric response to the SST variability over the wUS during boreal summer on the multidecadal timescale. In contrast to winter, relatively weaker influence of atmospheric internal variability (e.g.

Deser et al. 2012) results in the larger $R$ during the summer, suggesting a potential predictability of summertime climate on the multidecadal timescale. Note that the DMV in summertime wUS climate is substantially weaker during the periods when PDO and AMO are in phase (Fig. 5), suggesting that the wUS $R$ could be sensitive to relative phase between the two modes.

\section{Summary and discussion}

By comparing observations and the large member ensemble AGCM simulations, we have evaluated the SST-forced atmospheric response in the middle latitudes for the recent 60 years. The anthropogenically-induced 
381

climate trends contributed to the long-term increase in mean temperature and frequency of hot summers over the wUS and the Northern Hemisphere land areas. On the decadal-to-multidecadal timescale, the remarkable SST-forced signal is identified in the wUS summertime climate. PDO and AMO tend to be in opposite phase since the late 20th century, resulting in the amplified DMV in the wUS climate. During the negative PDO and positive AMO periods, low-level northerly wind anomaly over the wUS and cyclonic circulation anomaly over the subtropical North Atlantic result in reduced moisture advection and summertime precipitation over central and western North America. The wave-like atmospheric circulation pattern associated with the DMV can largely be reproduced by the AGCM runs and the idealized atmospheric simulations, indicating the importance of atmospheric teleconnections initiated by the tropical diabatic heating associated with the negative PDO and positive AMO. The recent wUS climate anomaly since the early 21 st century (persistent warm and dry condition) can partly be attributed to the DMV modes over the Pacific and Atlantic. The robust forced component of wUS summertime climate anomalies suggests a potential predictability on multidecadal timescale.

In this study, we only focused on the atmospheric variables including air temperature, precipitation and atmospheric circulation. SAT variation over land is also tightly associated with the regional hydrological cycle (runoff, precipitation minus evaporation, and soil moisture content; Seneviratne et al. 2010; Langford et al. 2014; Chikamoto et al. 2015; Yoon and Leung 2015). Variation in soil moisture (including drought) influences on the surface energy balance and resultant variations in frequency of extreme climate events including heat waves (Mueller and Seneviratne 2012). The effect of land hydrological cycle and underlying physical mechanisms should be examined in future studies. 
response (i.e. high statistical significance despite the substantial internal atmospheric variability in the middle

402

403

404

405

406

407

408

409

410

411

412

latitudes; e.g. Mori et al. 2014). The good reproducibility of the global climate variations highlights the potential for probabilistic attribution studies. We only examined monthly-mean data, but extreme climate phenomena on the sub-daily, daily, and weekly timescales should be further examined (i.e. tropical cyclones, atmospheric blocking, severe storms and resultant temperature, wind and precipitation extremes). In addition, the high resolution model is suitable for examining variations in regional atmospheric circulation and rainfall patterns induced by orography (Xie et al. 2006; Endo et al. 2012; Kusunoki and Arakawa 2012; Langford et al. 2014; Nakaegawa et al. 2014). The use of this ensemble dataset also aids risk assessments via statistical analyses of the high-impact climate events.

\section{Acknowledgements}

The authors thank anonymous reviewers for giving us constructive comments. This work was supported by the Program for Risk Information on Climate Change (SOUSEI program) and the Data Integration and Analysis System (DIAS) sponsored by the Ministry of Education, Culture, Sports, Science and Technology (MEXT), Japan. The Earth Simulator was used to develop the d4PDF ensemble dataset as "Strategic Project with Special Support" of JAMSTEC. The d4PDF dataset is available via DIAS website (http://dias-dss.tkl.iis.u-tokyo.ac.jp/ddc/viewer?ds=d4PDF_GCM\&lang=en). 
Adler RF, Huffman GJ, Chang A et al (2003) The Version-2 Global Precipitation Climatology Project (GPCP)

Brewer M, Mass C (2016) Projected changes in heat extremes and associated synoptic/mesoscale conditions over

Brönnimann S, Fischer AM, Rozanov E, Poli P, Compo GP, Sardeshmukh PD (2015) Southward shift of the northern tropical belt from 1945 to 1980 . Nature Geosci 8:969-974 
Delworth TL, Zeng F, Rosati A, Vecchi G, Wittenberg A (2015) A link between the hiatus in global warming and North American drought. J Clim 28:3834-3845

Deser C, Phillips AS, Hurrell JW (2004) Pacific interdecadal climate variability: linkages between the tropics and the North Pacific during boreal winter since 1900. J Clim 17:3109-3124

Deser C, Knutti R, Solomon S, Phillips AS (2012) Communication of the role of natural variability in future North American climate. Nature Clim Change 2:775-779

Diffenbaugh NS, Swain DL, Touma D (2015) Anthropogenic warming has increased drought risk in California. Proc Natl Acad Sci USA 112:3931-3936

Ding Q, Wallace JM, Battisti DS, Steig EJ, Gallant AJE, Kim H.-J. Geng L (2014) Tropical forcing of the recent rapid Arctic warming in northeastern Canada and Greenland. Nature 509:209-212

Endo H, Kitoh A, Ose T, Mizuta R, Kusunoki S (2012) Future changes and uncertainties in Asian precipitation simulated by multiphysics and multi-sea surface temperature ensemble experiments with high-resolution Meteorological Research Institute atmospheric general circulation models (MRI-AGCMs). J Geophys Res 117:D16118. doi:10.1029/2012JD017874

England MH et al (2014) Recent intensification of wind-driven circulation in the Pacific and the ongoing warming hiatus. Nature Clim Change 4:222-227

Eyring V et al (2005) A strategy for process-oriented validation of coupled chemistry-climate models. Bull Am Meteorol Soc 86:1117-1133 
456

457

458

459

460

461

462

463

464

Feng S, Hu Q, Oglesby RJ (2011) Influence of Atlantic sea surface temperatures on persistent drought in North America. Clim Dyn 37:569-586. doi:10.1007/s00382-010-0835-x

Fyfe JC et al (2016) Making sense of the early-2000s warming slowdown. Nature Clim Change 6:224-228

Gu F, Adler RF, Huffman GJ (2016) Long-term changes/trends in surface temperature and precipitation during the satellite era (1979-2012). Clim Dyn 46:1091-1105

Hansen J, Sato M, and Ruedy R (2012) Perception of climate change. Proc Natl Acad Sci USA 109:E2415E2423

Harris I, Jones PD, Osborn TJ, Lister DH (2014) Updated high-resolution grids of monthly climatic observations - the CRU TS3.10 Dataset. Int J Climatol 34:623-642

Hagos S et al (2010) Estimates of tropical diabatic heating profiles: Commonalities and uncertainties. J Clim $23: 542-558$

Hawkins E, Sutton R (2009) The potential to narrow uncertainty in regional climate predictions. Bull Am Meteorol Soc 90:1095-1107

Hirahara S, Ishii M, Fukuda Y (2014) Centennial-scale sea surface temperature analysis and its uncertainty. J Clim 27:57-75

Hoerling M, Eischeid J, Perlwitz J (2010) Regional precipitation trends: distinguishing natural variability from anthropogenic forcing. J Climate 23:2131-2145 
473

474

475

476

477

478

479

Hu Q, Feng S (2012) AMO- and ENSO-driven summertime circulation and precipitation variations in North America. J Clim 25:6477-6495

Hu Q, Feng S, Oglesby RJ (2011) Variations in North American summer precipitation driven by the Atlantic Multidecadal Oscillation. J Clim 24:5555-5570

IPCC (2013) Summary for policymakers, in Climate Change 2013: The Physical Science Basis, edited by Stocker TF et al, pp. 3-29, Cambridge Univ Press, Cambridge, UK, and New York. doi:10.1017/cbo9781107415324.004

Jones GS, Stott PA, Christidis N (2013) Attribution of observed historical near surface temperature variations to anthropogenic and natural causes using CMIP5 simulations. J Geophys Res Atmos 118:4001-4024. doi:10.1002/jgrd.50239

Kamae Y, Shiogama H, Watanabe M, Kimoto M (2014a) Attributing the increase in Northern Hemisphere hot summers since the late 20th century. Geophys Res Lett 41:5192-5199

Kamae Y, Watanabe M, Kimoto M, Shiogama H (2014b) Summertime land-sea thermal contrast and atmospheric circulation over East Asia in a warming climate_-Part I: Past changes and future projections. Clim Dyn 43:2553-2568

Kamae Y, Shiogama H, Watanabe M, Ishii M, Ueda H, Kimoto M (2015) Recent slowdown of tropical upper tropospheric warming associated with Pacific climate variability. Geophys Res Lett 42: 2995-3003 
490

491

492

493

494

Kobayashi S et al (2015) The JRA-55 Reanalysis: General specifications and basic characteristics. J Meteorol Soc Jpn 93:5-48

Kosaka Y, Xie S-P (2013) Recent global-warming hiatus tied to equatorial Pacific surface cooling. Nature $501: 403-407$

Kushnir Y, Seager R, Ting MF, Naik N, Nakamura J (2010) Mechanisms of tropical Atlantic SST influence on North American precipitation variability. J Clim 23:5610-5628

Kusunoki S, Arakawa O (2012) Change in the precipitation intensity of the East Asian summer monsoon projected by CMIP3 models. Clim Dyn 38:2055-2072

Langford S, Stevenson S, Noone D (2014) Analysis of low-frequency precipitation variability in CMIP5 historical simulations for southwestern North America. J Clim 27:2735-2756

Li X, Xie S-P, Gille ST, Yoo C (2016) Atlantic-induced pan-tropical climate change over the past three decades. Nature Clim Change 6:275-279

Luo JJ, Sasaki W, Masumoto Y (2012) Indian Ocean warming modulates Pacific climate change. Proc Natl Acad Sci USA 109:18701-18706

Madden RA (1976) Estimates of the natural variability of time-averaged sea-level pressure. Mon Wea Rev 104:942-952

Mantua NJ, Hare SR, Zhang Y, Wallace JM, Francis RC (1997) A Pacific interdecadal climate oscillation with impacts on salmon production. Bull Am Meteorol Soc 78:1069-1079 
McGregor S et al (2014) Recent Walker circulation strengthening and Pacific cooling amplified by Atlantic warming. Nature Clim Change 4:888-892

Meehl GA, Hu AX (2006) Megadroughts in the Indian monsoon region and southwest North America and a mechanism for associated multidecadal Pacific sea surface temperature anomalies. J Clim 19:1605-1623

Meehl GA, Arblaster JM, Tebaldi C (2007) Contributions of natural and anthropogenic forcing to changes in temperature extremes over the U.S. Geophys Res Lett 34:L19709. doi:10.1029/2007GL030948

Meehl GA, Arblaster JM Branstator G (2012) Mechanisms contributing to the warming hole and the consequent U.S. east-west differential of heat extremes. J Clim 25:6394-6408

Mei W, Xie S-P, Zhao M (2014) Variability of tropical cyclone track density in the North Atlantic: Observations and high-resolution simulations. J Clim 27:4797-4814

Mei W, Xie S-P, Zhao M, Wang Y (2015) Forced and internal variability of tropical cyclone track density in the western North Pacific. J Clim 28:143-167

Mizuta R, Yoshimura H, Murakami H, Matsueda M, Endo H, Ose T, Kamiguchi K, Hosaka M, Sugi M, Yukimoto S, Kusunoki S, Kitoh A (2012) Climate simulations using MRI-AGCM with 20-km grid. J Meteorol Soc Jpn 90A:235-260

Mizuta R et al (2016) Over 5000 years of ensemble future climate simulations by $60 \mathrm{~km}$ global and $20 \mathrm{~km}$ regional atmospheric models. Bull Am Meteorol Soc (submitted) 
Mo K, Schemm J, Yoo S (2009) Influence of ENSO and the Atlantic Multidecadal Oscillation on drought over the United States. J Clim 22:5962-5982

Mohino E, Janicot S, Bader J (2011) Sahel rainfall and decadal to multi-decadal sea surface temperature variability. Clim Dyn 37:419-440

Mori M, Watanabe M, Shiogama H, Inoue J, Kimoto M (2014) Robust Arctic sea-ice influence on the frequent Eurasian cold winters in past decades. Nat Geosci 7:869-873

Mueller B, Seneviratne SL (2012) Hot days induced by precipitation deficits at the global scale. Proc Natl Acad Sci USA 109:12398-12403

Murakami H, Mizuta R, Shindo E (2012) Future changes in tropical cyclone activity projected by multi-physics and multi-SST ensemble experiments using the 60-km-mesh MRI-AGCM. Clim Dyn 39:2569-2584

Nakaegawa T, Kitoh A, Murakami H, Kusunoki S (2014) Annual maximum 5-day rainfall total and maximum number of consecutive dry days over Central America and the Caribbean in the late twenty-first century projected by an atmospheric general circulation model with three different horizontal resolutions. Theor Appl Climatol 116:155-168

Newman M. et al (2016) The Pacific Decadal Oscillation, revisited. J Clim 29:4399-4427

Perkins SE, Alexander LV, Nairn JR (2012) Increasing frequency, intensity and duration of observed global heatwaves and warm spells. Geophys Res Lett 39:L20714. doi:10.1029/2012GL053361 
Prein AF, Holland GJ, Rasmussen RM, Clark MP, Tye MR (2016) Running dry: The U.S. Southwest's drift into a drier climate state. Geophys Res Lett 43:1272-1279

Power S, Casey T, Folland C, Colman A, Mehta V (1999) Interdecadal modulation of the impact of ENSO on Australia. Clim Dyn 15:319-324

Rayner NA et al (2003) Global analyses of sea surface temperature, sea ice, and night marine air temperature since the late nineteenth century. J Geophys Res 108(D14):4407. doi:10.1029/2002JD002670

Seager R, Hoerling M (2014) Atmosphere and ocean origins of North American droughts. J Clim 27:4581-4606

Seager R, Kushnir Y, Herweijer C, Naik N, Velez J (2005) Modeling of tropical forcing of persistent droughts and pluvials over western North America: 1856-2000. J Clim 18:4068-4091

Seneviratne SI, Corti T, Davin EL, Hirschi M, Jaeger EB, Lehner I, Orlowsky B, Teuling AJ (2010) Investigating soilmoisture-climate interactions in a changing climate: A review. Earth Sci Rev 99:125-161

Sheffield J et al (2013) North American climate in CMIP5 experiments. Part II: Evaluation of historical simulations of intraseasonal to decadal variability. J Clim 26:9247-9290

Shibata K, Deushi M, Sekiyama TT, Yoshimura H (2005) Development of an MRI chemical transport model for the study of stratospheric chemistry. Pap Meteor Geophys 55:75-118

Shige S, Takayabu YN, Tao W-K (2008) Spectral retrieval of latent heating profiles from TRMM PR data. Part III: Estimating apparent moisture sink profiles over tropical oceans. J Appl Meteorol Climatol 47:620-640 
559

560

561

Shiogama H, Watanabe M, Imada Y, Mori M, Kamae Y, Ishii M, Kimoto M (2014) Attribution of the June-July 2013 heat wave in the southwestern United States. SOLA 10:122-126

Shiogama $\mathrm{H}$ et al (2016) Attributing historical changes in probabilities of record-breaking daily temperature and precipitation extreme events. SOLA 12:225-231

Sippel S, Zscheischler J, Heimann M, Otto FEL, Peters J, Mahecha MD (2015) Quantifying changes in climate variability and extremes: Pitfalls and their overcoming. Geophys Res Lett 42:9990-9998

Sutton RT, Hodson DLR (2005) Atlantic Ocean forcing of North American and European summer climate. Science 309:115-118

Sutton RT, Hodson DLR (2007) Climate response to basin-scale warming and cooling for the North Atlantic Ocean. J Clim 20:891-907

Ting M, Wang H (1997) Summertime US precipitation variability and its relation to Pacific sea surface temperature. J Clim 10: 1853-1873

Trenberth KE, Shea DJ (2006) Atlantic hurricanes and natural variability in 2005. Geophys Res Lett 33:L12704. doi:10.1029/2006GL026894

Trenberth KE, Fasullo JT, Branstator G, Phillips S (2014) Seasonal aspects of the recent pause in surface warming. Nature Clim Change 4:911-916

Ueda H, Kamae Y, Hayasaki M, Kitoh A, Watanabe A, Miki Y, Kumai A (2015) Combined effects of recent Pacific cooling and Indian Ocean warming on the Asian monsoon. Nature Comm 6:8854 
Wallace JM, Deser C, Smoliak BV, Phillips AS (2015) Attribution of climate change in the presence of internal variability. in Climate Change: Multidecadal and Beyond, World Scientific Series on Asia-Pacific Weather and Climate Vol. 6, edited by Chang CP, Ghil M, Latif M, Wallace JM, pp. 1-29, World Scientific Publishing

Wang B, Liu J, Kim HJ, Webster PJ, Yim SY, Xiang B (2013) Northern Hemisphere summer monsoon intensified by mega-El Nino/southern oscillation and Atlantic multidecadal oscillation. Proc Natl Acad Sci

$$
\text { USA 110:5347-5352 }
$$

Wang H, Schubert S (2014) The precipitation response over the continental United States to cold tropical Pacific sea surface temperatures. J Clim 27:5036-5055

Watanabe M, Kimoto M (2000) Atmosphere-ocean thermal coupling in the North Atlantic: a positive feedback. Q J Roy Meteorol Soc 126:3343-3369

Watanabe M, Shiogama H, Tatebe H, Hayashi M, Ishii M, Kimoto M (2014) Contribution of natural decadal variability to global-warming acceleration and hiatus. Nature Clim Change 4:893-897

Xie S-P, Xu H, Saji NH, Wang Y, Liu WT (2006) Role of narrow mountains in large-scale organization of Asian monsoon convection. J Clim 19:3420-3429

Xie S-P et al (2015) Towards predictive understanding of regional climate change. Nature Clim Change 5:921930 
Yanai M, Tomita T (1998) Seasonal and interannual variability of atmospheric heat sources and moisture sinks as determined from NCEP-NCAR reanalysis. J Clim 11:463-482

Yoon J-H, Leung LR (2015) Assessing the relative influence of surface soil moisture and ENSO SST on precipitation predictability over the contiguous United States. Geophys Res Lett 42:5005-5013

Yukimoto S et al. (2011) Meteorological Research Institute-Earth System Model v1 (MRI-ESM1)—model description. Tech Rep Meteor Res Inst 64, p 88 [available at http://www.mri-jma.go.jp/Publish/Technical/DATA/VOL_64/index_en.html]

Zhang X, Hegerl G, Zwiers F, Kenyon J (2005) Avoiding inhomogeneity in percentile-based indices of temperature extremes. J Clim 18:1641-1651

Zhang R, Delworth TL (2006) Impact of Atlantic multidecadal oscillations on India/Sahel rainfall and Atlantic hurricanes. Geophys Res Lett 33:L17712. doi:10.1029/2006GL026267

Zhou Y, Wu Z (2016) Possible impacts of mega-El Niño/Southern Oscillation and Atlantic multidecadal oscillation on Eurasian heat wave frequency variability. Q J Roy Meteorol Soc 142:1647-1661 
Table 1. Anomalies over the western US during 2000-2010 relative to 1978-1999. ALL and NW lines represent results of 100-member AGCM simulations and non-warming simulations, respectively. ANT line is anthropogenic influence, determined by ALL minus NW (Sect. 2.2). Uncertainty ranges represent $95 \%$ confidence intervals 
Fig. 1 (a) Surface air temperature (SAT; K) anomalies averaged over the Northern Hemisphere land areas during June-July-August (JJA) relative to 1958-1990 mean. Black and gray lines represent JRA-55 (1958-2010) and CRU TS v3.23 (1901-2010), respectively. Red and blue lines and shadings are ensemble mean and 95\% anomalies (relative to 1958-1990) of areal fraction of hot summers (\%) determined by mean and two standard deviation of SAT during 1958-2010 (see section 2.4)

Fig. 2 (a) JJA-mean SAT anomaly (K) during 2000-2010 relative to 1978-1999 in JRA-55. Stipples indicate regions with statistically significant anomaly at $95 \%$ confidence level. Black rectangle represents the western US region used in this study. (b) Similar to (a) but for ALL run. (c, d) Similar to (a, b) but for frequency of hot summers $(\%)$

Fig. 3 (a, b) Similar to Fig. 1a, b but for SAT and frequency of hot summers averaged over the western US (black rectangle in Fig. 2). (c) Precipitation anomalies $\left(\mathrm{mm}^{-1 a y}{ }^{-1}\right)$ over the western US. (d-f) Similar to (a- 
Fig. 4 Composite anomalies of JJA-mean precipitation and sea surface temperature (SST) for "negative PDO and positive AMO" period (1951-1965 and 2003-2010) minus "positive PDO and negative AMO" period (1978-1999). (a) Land precipitation (mm day ${ }^{-1}$ ) in CRU TS v3.23. (b) Ensemble mean of ALL run. Only statistically significant anomalies at 95\% confidence level are shown. (c) SST (K) in HadISST

Fig. 5 Similar to Fig. 4, but for "negative PDO and negative AMO" period (1966-1977) minus "positive PDO

Fig. 7 (a) Composite anomalies of JJA-mean atmospheric circulation for "negative PDO and positive AMO" period (1958-1965 and 2003-2010) minus "positive PDO and negative AMO" period (1978-1999) in

Fig. 6 JJA-mean precipitation anomaly $\left(\mathrm{mm} \mathrm{day}^{-1}\right)$ in GPCP during 2003-2010 relative to 1979-1999. Stipples indicate regions with statistically significant anomaly at $95 \%$ confidence level. Blue and red rectangles are the eastern tropical Pacific (ePac) and tropical Atlantic (tAtl) regions used in Fig. 8, respectively 

the ALL run. Only anomalies with $95 \%$ confidence level are shown

Fig. 8 Climatological (1951-2010) atmospheric heating rate $\left(\mathrm{K} \mathrm{day}^{-1}\right)$ due to large-scale condensation and convective precipitation in JRA-55. Black solid and gray dashed lines are averages over the ePac and tAtl regions shown in Fig. 6

Fig. 9 Similar to Fig. 7, but for atmospheric response to tropical diabatic heating simulated in Linear Baroclinic $140^{\circ} \mathrm{W}, 20^{\circ} \mathrm{N}$ (blue circle). Contours are geopotential height at $850 \mathrm{hPa}$ level $( \pm 0.1,0.5,1 \mathrm{~m})$. (b) Similar to (a) but for middle-tropospheric heating over tAtl region centered at $5^{\circ} \mathrm{W}, 12^{\circ} \mathrm{N}$ (red circle)

Fig. 10 Signal-to-noise ratio during JJA determined by a ratio of standard deviation in 100-member ensemble mean to standard deviation among the members. (a) High-frequency and (b) low-frequency SAT variation 
674

\begin{tabular}{cccc}
\hline & SAT $(\mathrm{K})$ & Hot summers $(\%)$ & Precipitation $\left(\mathrm{mm} \mathrm{day}^{-1}\right)$ \\
\hline CRU TS v3.23 & $0.61 \pm 0.57$ & $2.64 \pm 3.93$ & $-0.14 \pm 0.15$ \\
\hline JRA-55 & $0.79 \pm 0.69$ & $4.20 \pm 4.58$ & \\
\hline ALL & $0.74 \pm 0.06$ & $4.14 \pm 0.53$ & $-0.09 \pm 0.02$ \\
\hline NW & $0.25 \pm 0.06$ & $0.76 \pm 0.42$ & $-0.04 \pm 0.02$ \\
\hline ANT & $0.49 \pm 0.08$ & $3.38 \pm 0.61$ & $-0.05 \pm 0.03$ \\
\hline
\end{tabular}



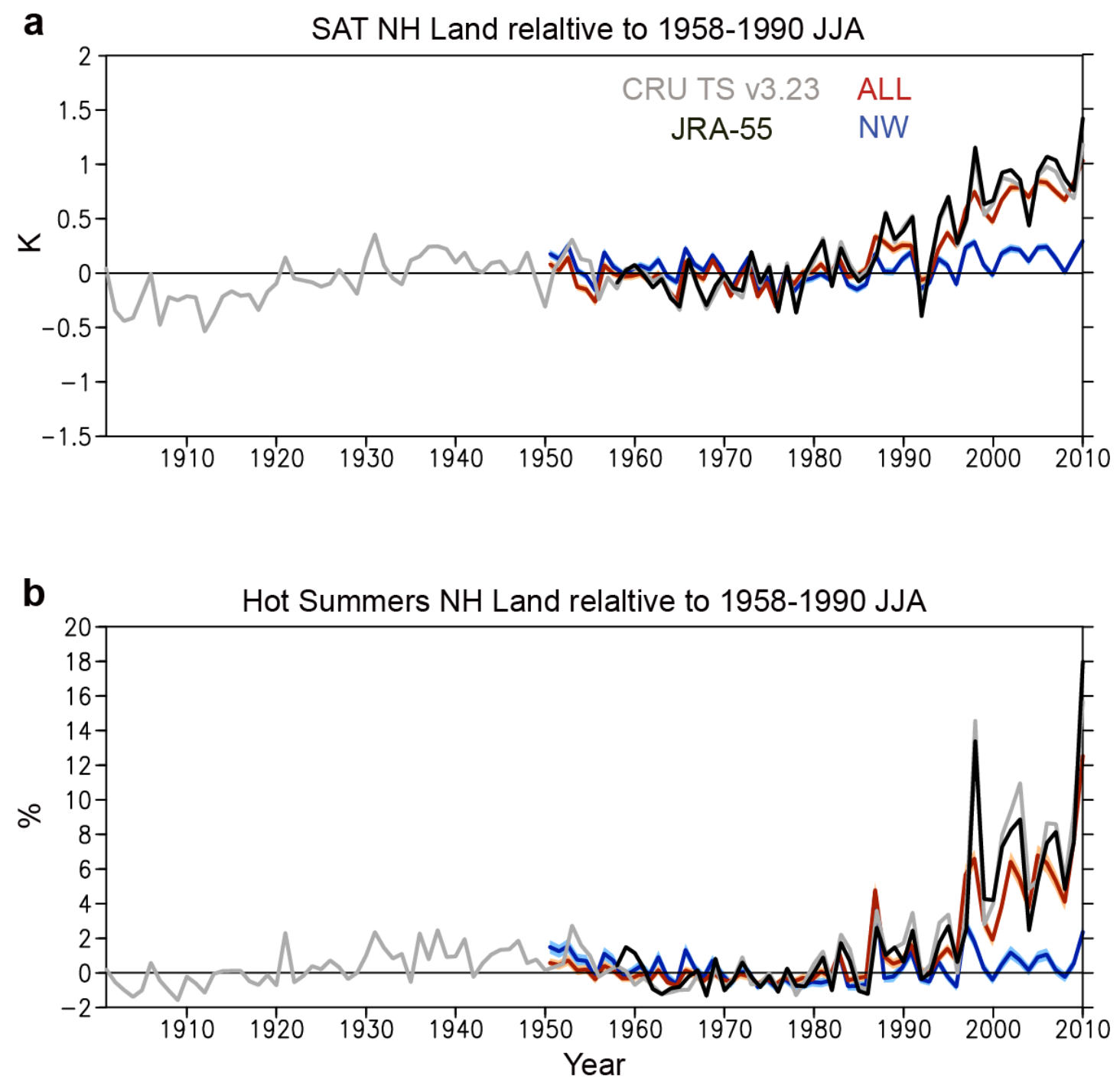

Fig. 1 (a) Surface air temperature (SAT; K) anomalies averaged over the Northern Hemisphere land areas during June-July-August (JJA) relative to 1958-1990 mean. Black and gray lines represent JRA-55 (1958-2010) and CRU TS v3.23 (1901-2010), respectively. Red and blue lines and shadings are ensemble mean and 95\% confidence interval of 100-member ALL and NW runs (1951-2010), respectively. (b) Similar to (a) but for anomalies (relative to 1958-1990) of areal fraction of hot summers (\%) determined by mean and two standard deviation of SAT during 1958-2010 (see section 2.4) 

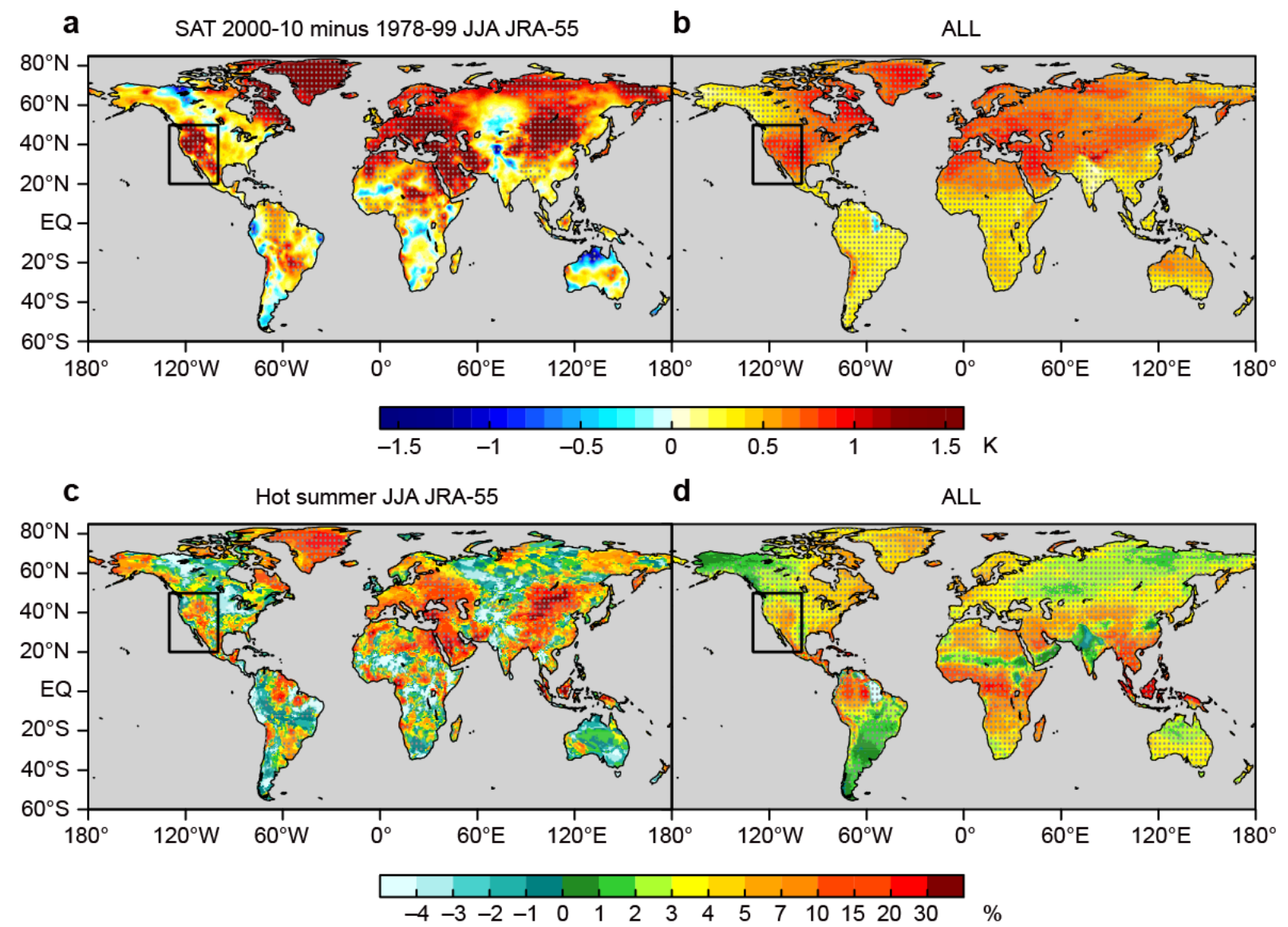

Fig. 2 (a) JJA-mean SAT anomaly (K) during 2000-2010 relative to 1978-1999 in JRA-55. Stipples indicate 


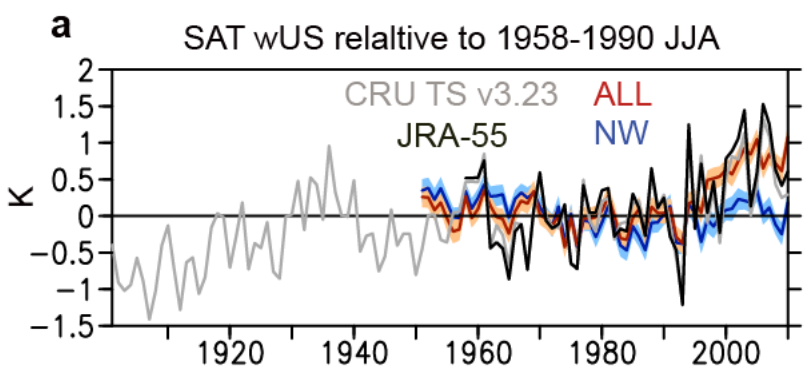

d Decadal
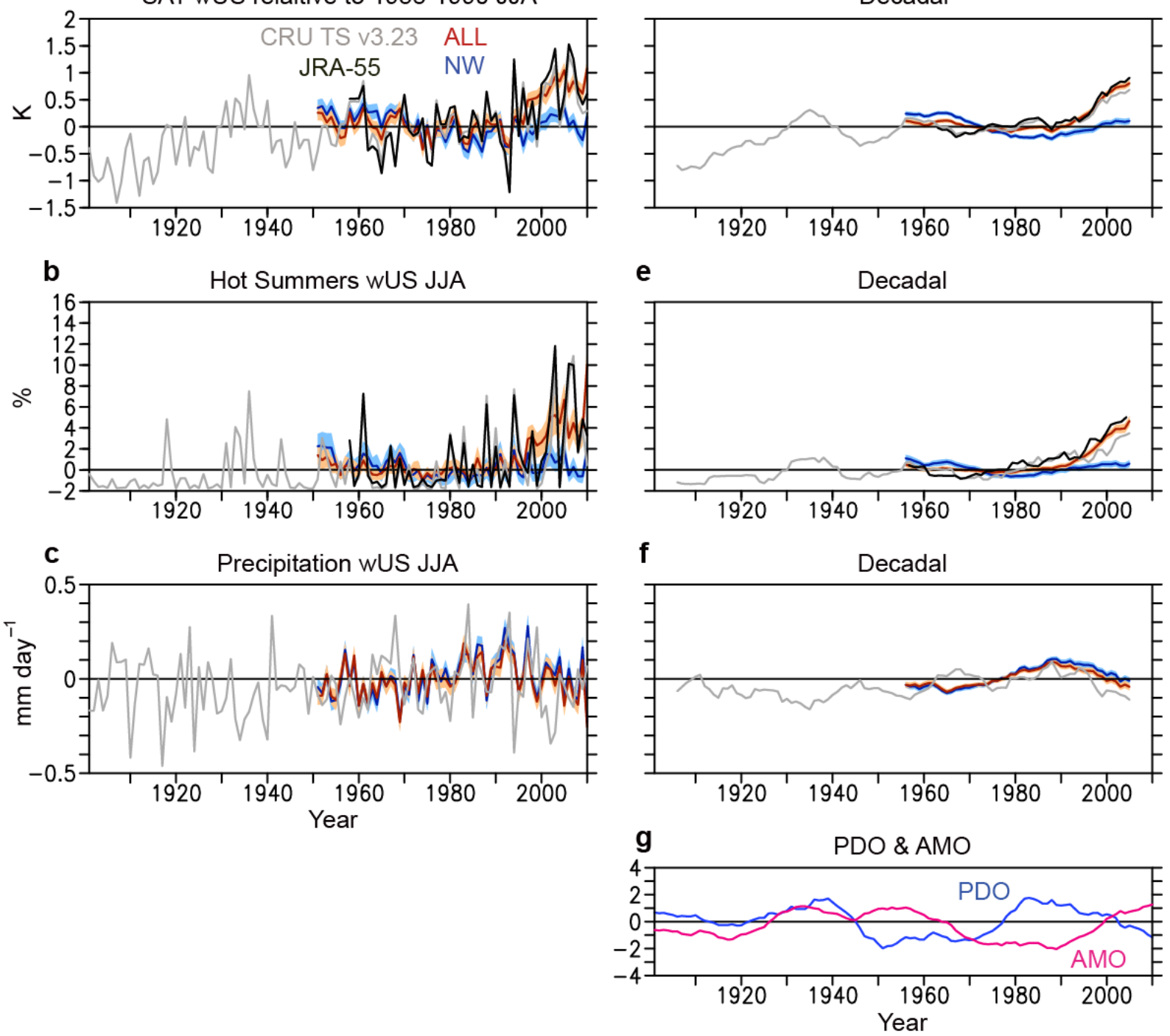

Fig. 3 (a, b) Similar to Fig. 1a, b but for SAT and frequency of hot summers averaged over the western US 

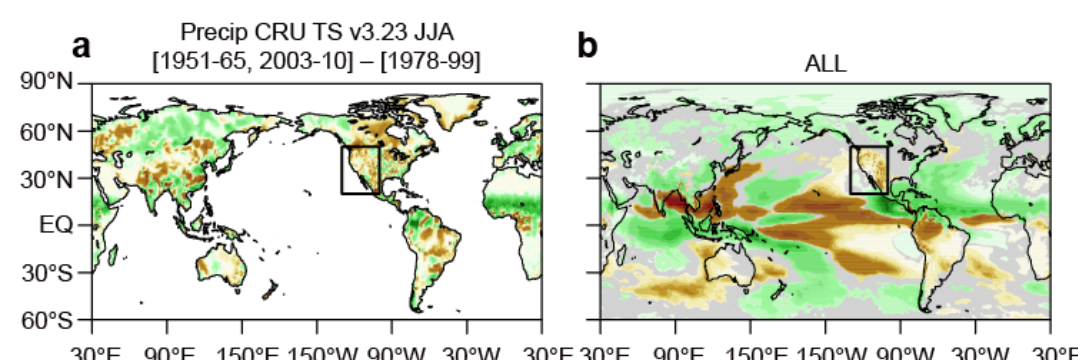

C
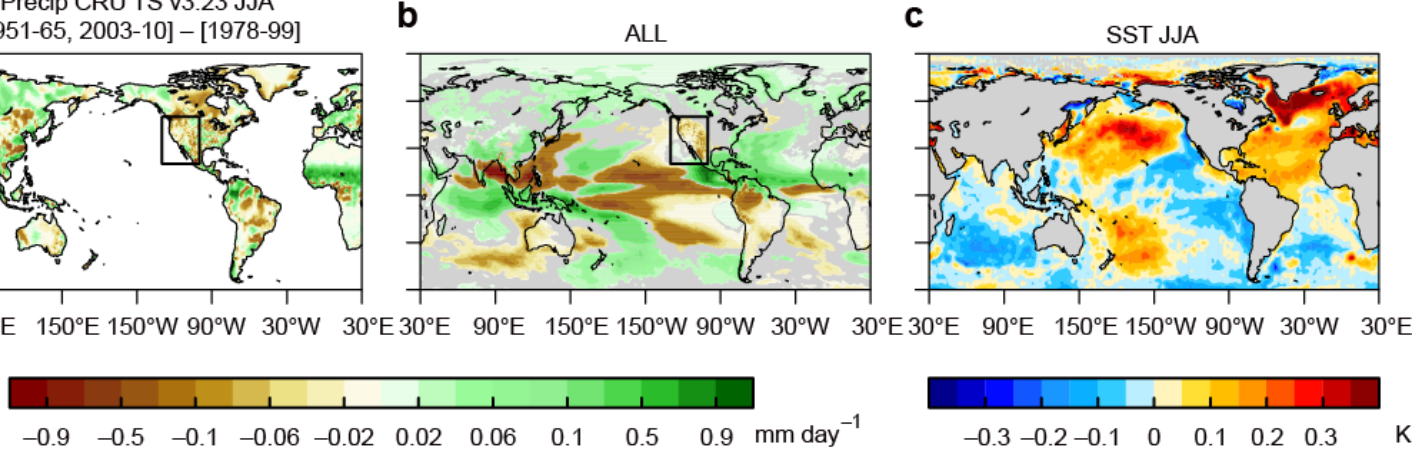

Fig. 4 Composite anomalies of JJA-mean precipitation and sea surface temperature (SST) for "negative PDO 


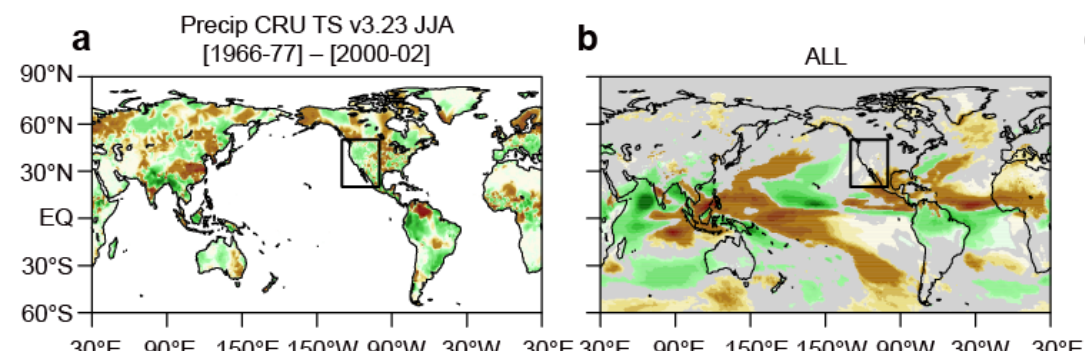

C SST JJA
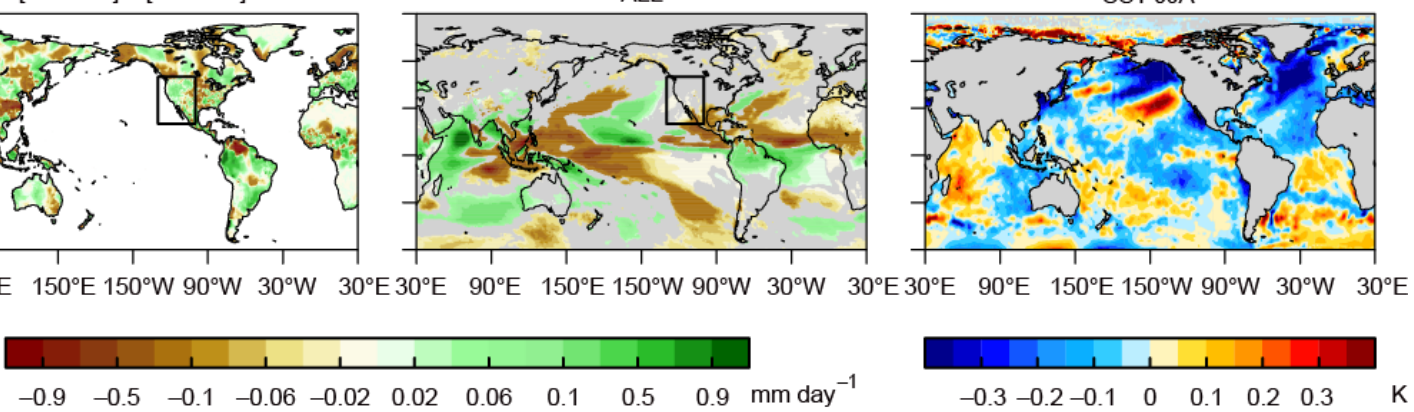

$\begin{array}{llllll}-0.3-0.2-0.1 & 0 & 0.1 & 0.2 & 0.3 & \mathrm{~K}\end{array}$

Fig. 5 Similar to Fig. 4, but for "negative PDO and negative AMO” period (1966-1977) minus "positive PDO 

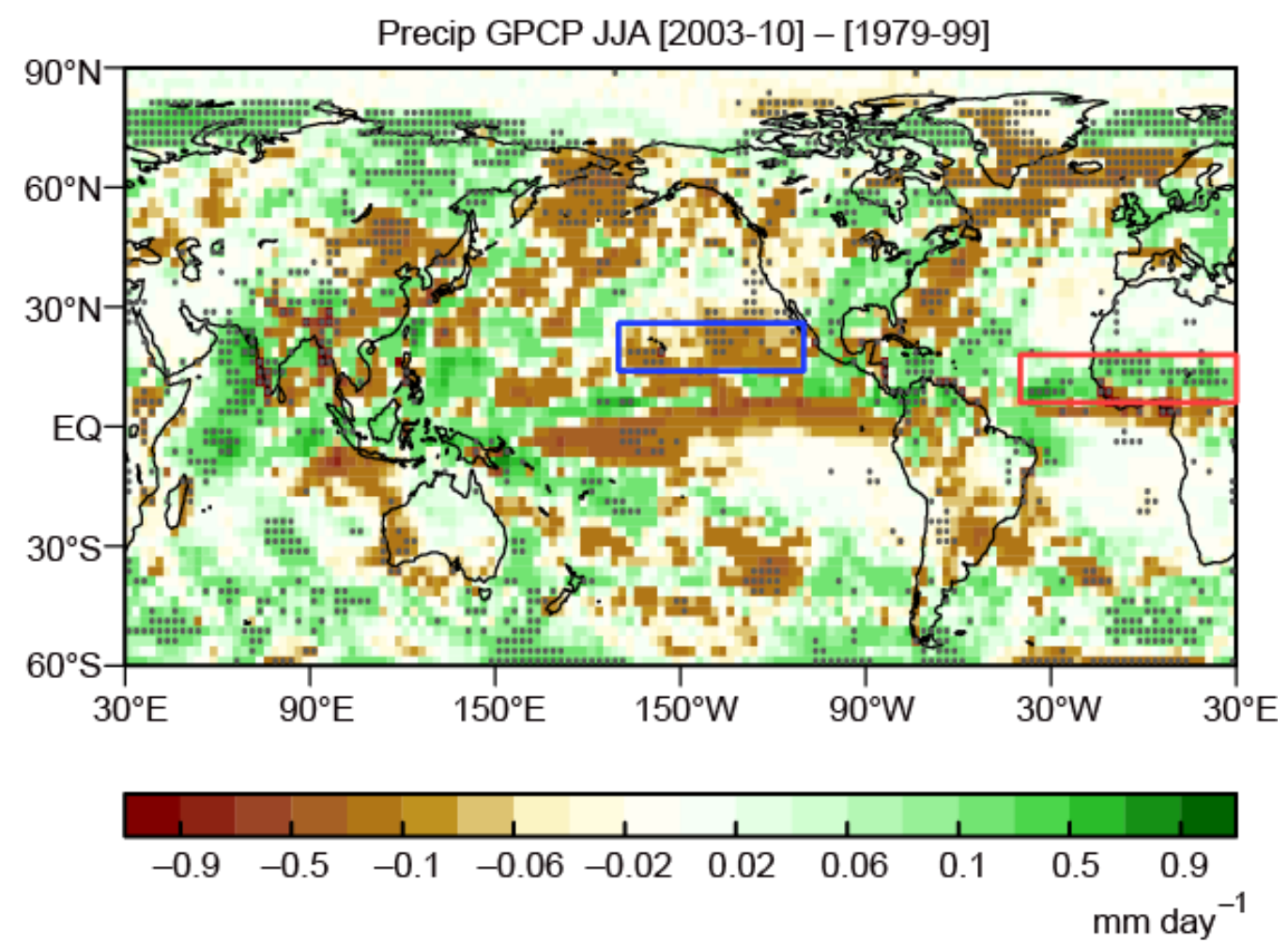

Fig. 6 JJA-mean precipitation anomaly $\left(\mathrm{mm} \mathrm{day}^{-1}\right)$ in GPCP during 2003-2010 relative to 1979-1999. Stipples indicate regions with statistically significant anomaly at $95 \%$ confidence level. Blue and red rectangles are 


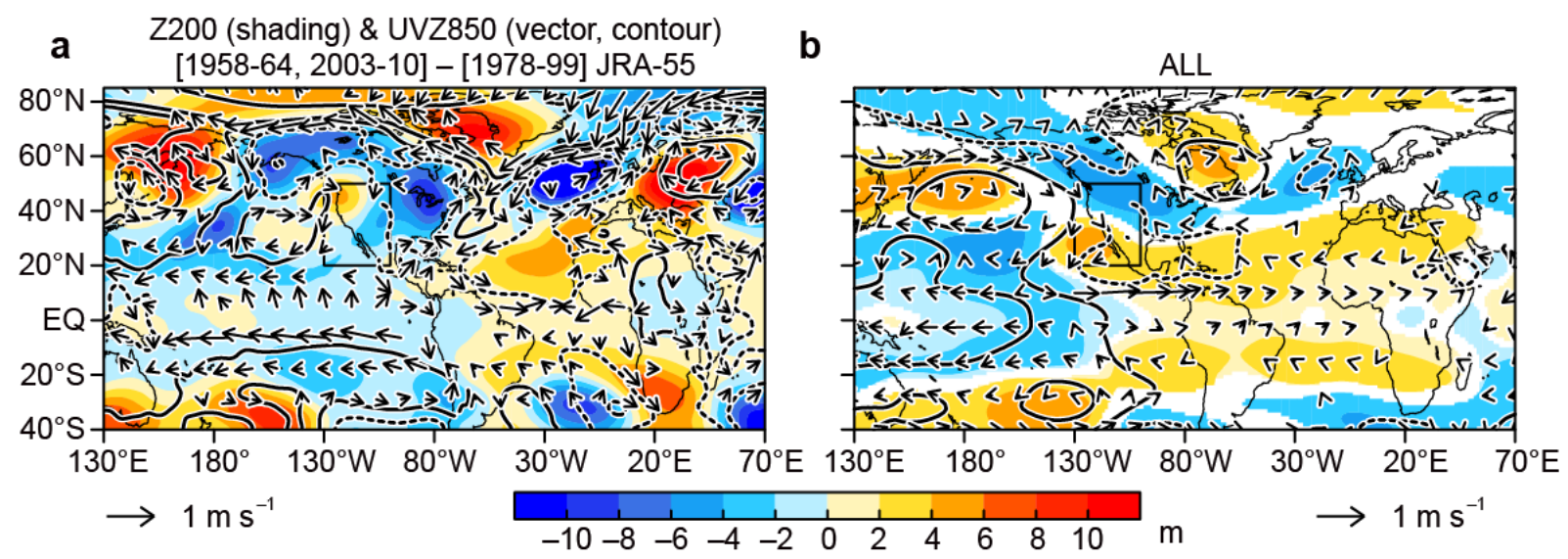

Fig. 7 (a) Composite anomalies of JJA-mean atmospheric circulation for "negative PDO and positive AMO" period (1958-1965 and 2003-2010) minus "positive PDO and negative AMO" period (1978-1999) in 


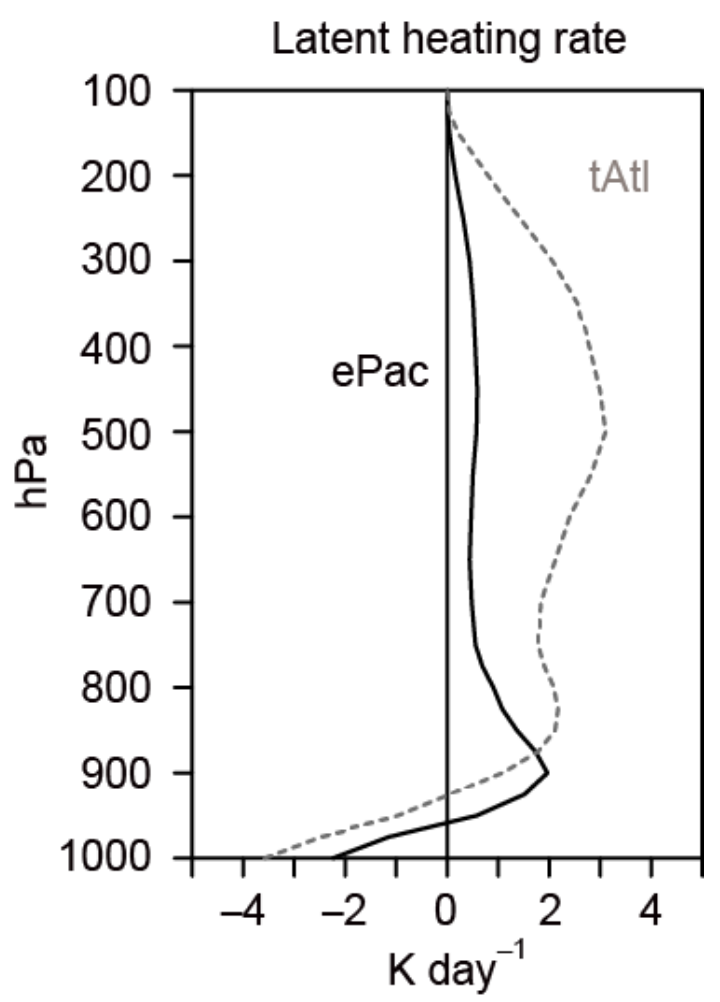

730

Fig. 8 Climatological (1951-2010) atmospheric heating rate $\left(\mathrm{K} \mathrm{day}^{-1}\right)$ due to large-scale condensation and 


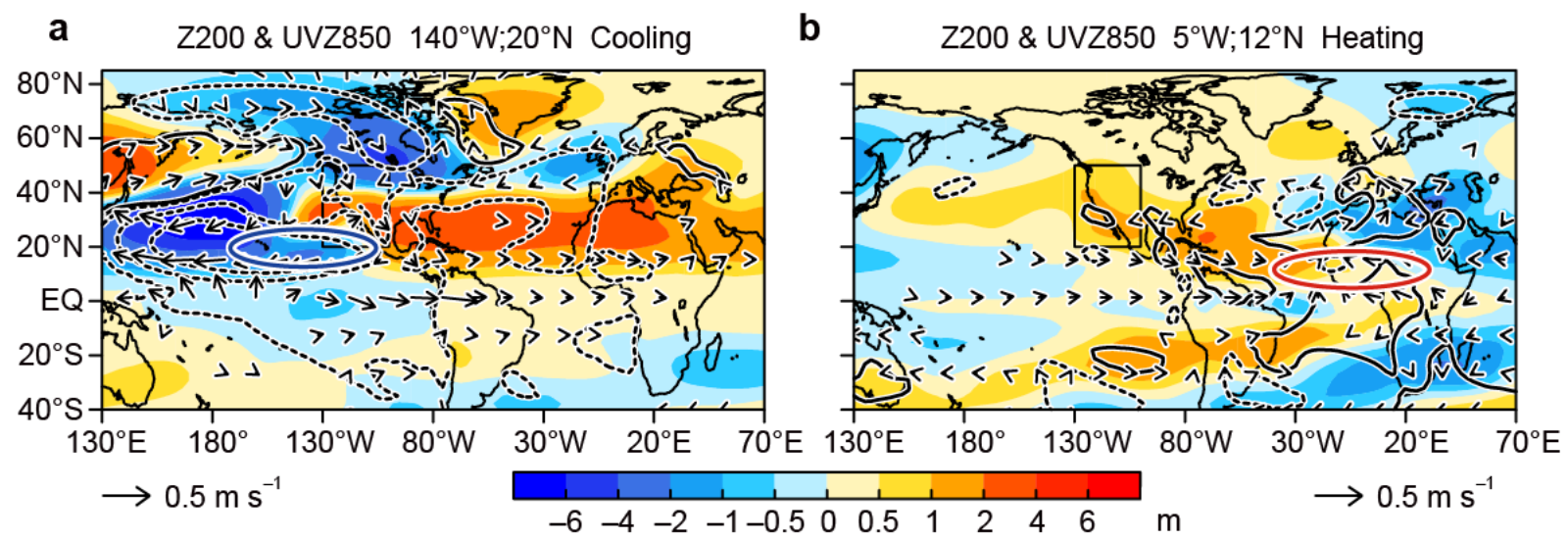

Fig. 9 Similar to Fig. 7, but for atmospheric response to tropical diabatic heating simulated in Linear Baroclinic 

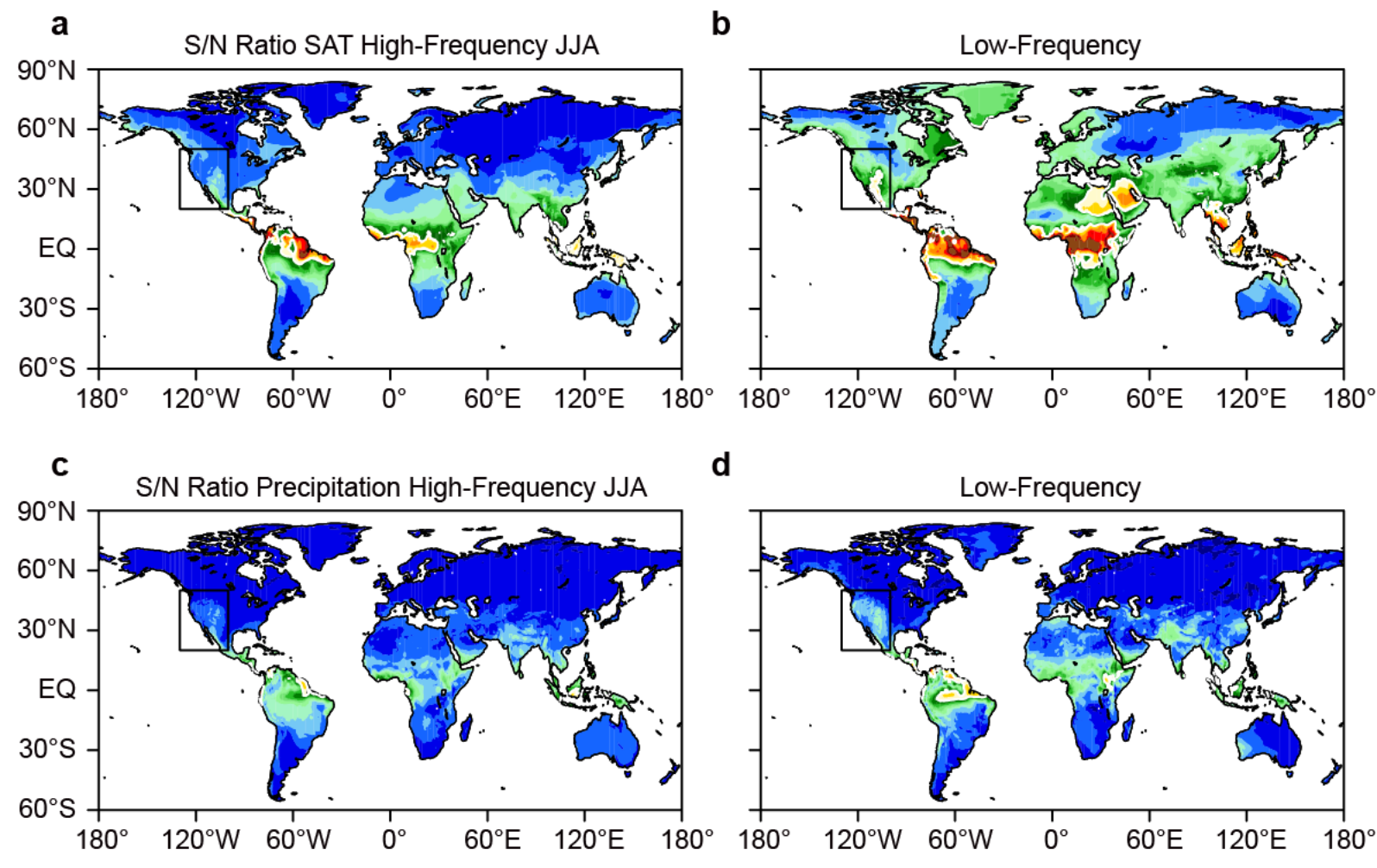

d
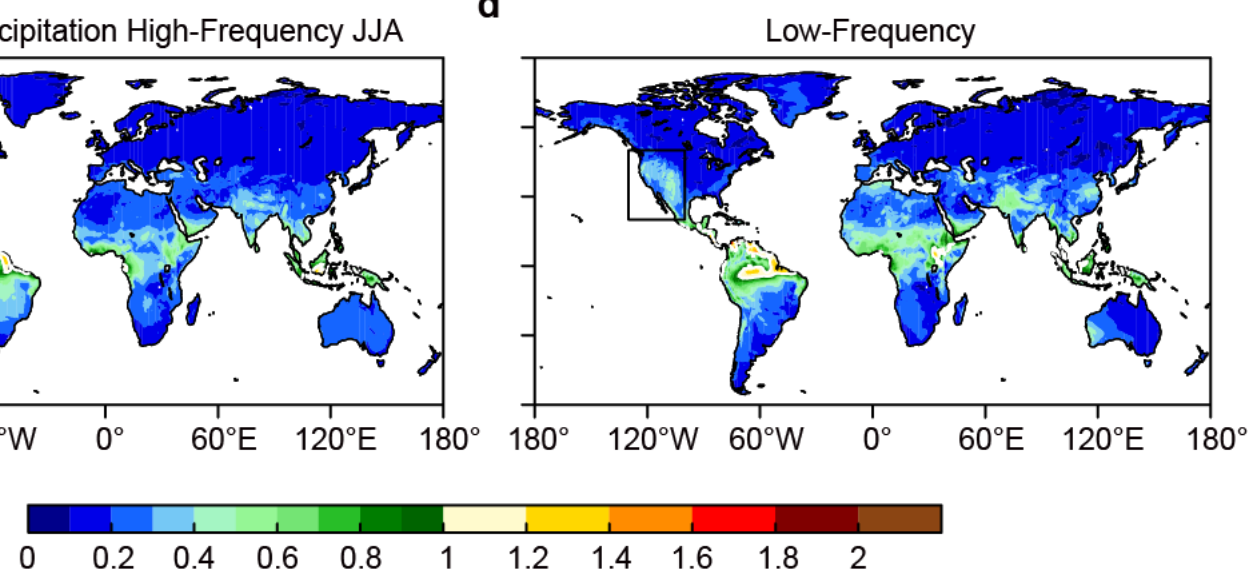

Fig. 10 Signal-to-noise ratio during JJA determined by a ratio of standard deviation in 100-member ensemble 

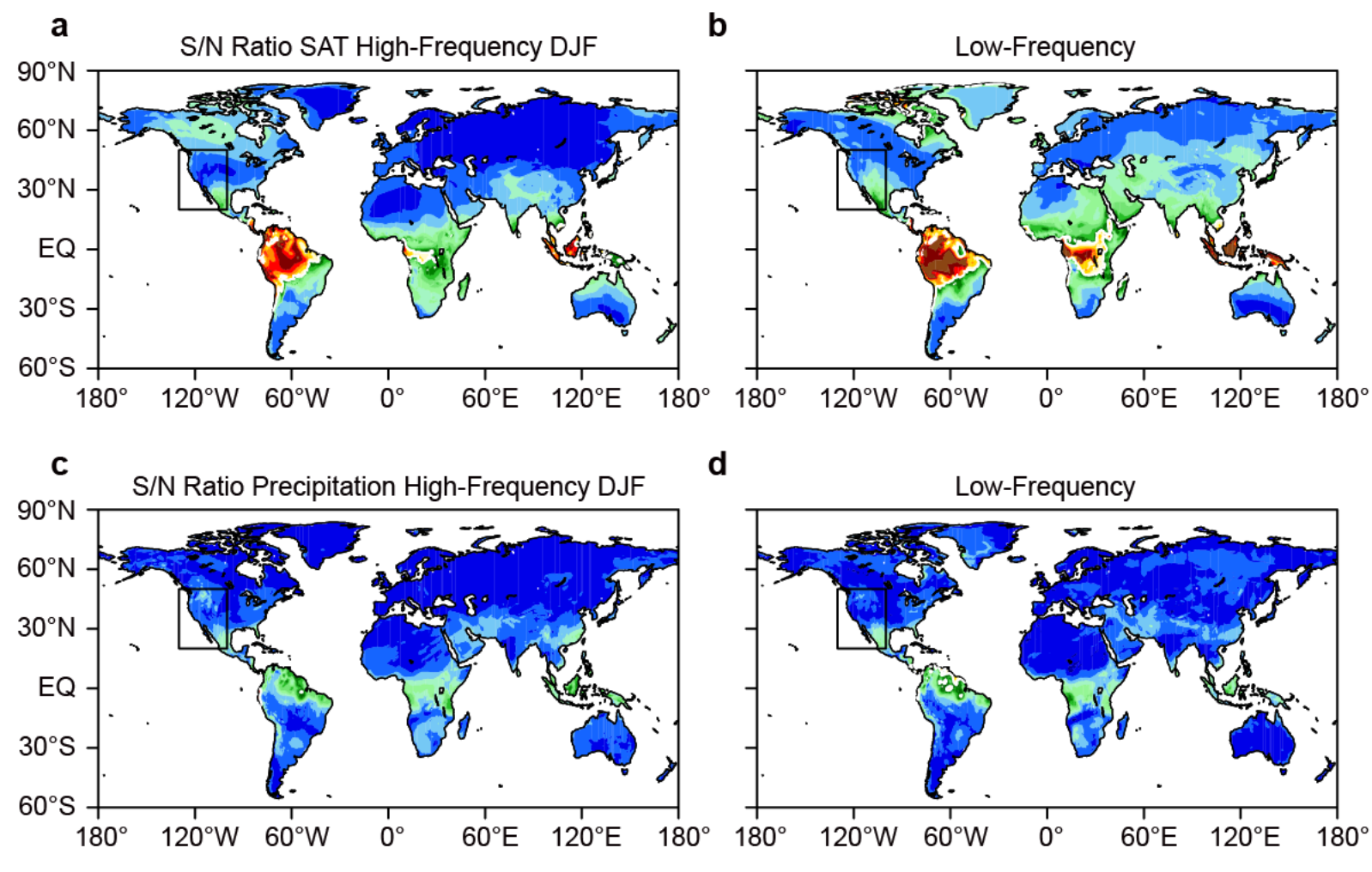

d
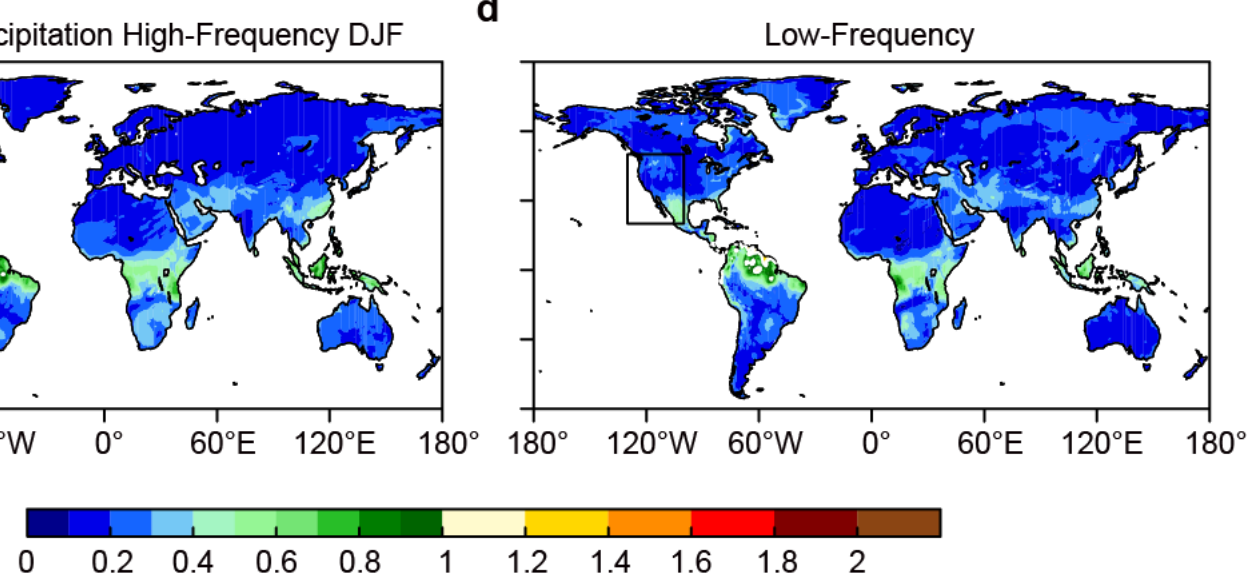

Fig. 11 Similar to Fig. 10, but for December-January-February (DJF) 